\title{
NMR resonance assignments of a hypoallergenic isoform of the major birch pollen allergen Bet $\mathrm{v} 1$
}

\author{
Linda Ahammer ${ }^{1} \cdot$ Sarina Grutsch $^{1} \cdot$ Michael Wallner $^{2} \cdot$ Fatima Ferreira $^{2} \cdot$ \\ Martin Tollinger ${ }^{1}$ (B)
}

Received: 3 March 2017 / Accepted: 5 August 2017 / Published online: 14 August 2017

(c) The Author(s) 2017. This article is an open access publication

\begin{abstract}
In Northern America and Europe a great number of people are suffering from birch pollen allergy and pollen related food allergies. The trigger for these immunological reactions is the $17.5 \mathrm{kDa}$ major birch pollen allergen Bet $\mathrm{v} 1$, which belongs to the family of PR-10 (pathogenesis-related) proteins. In nature, Bet v 1 occurs as a mixture of various isoforms that possess different immunological properties despite their high sequence identities. Bet v 1.0102 (Bet $\mathrm{v}$ $1 \mathrm{~d}$ ), which is investigated here, is a hypoallergenic isoform of Bet $\mathrm{v} 1$ and a potential candidate for allergen-specific immunotherapy. We assigned the backbone and side chain ${ }^{1} \mathrm{H},{ }^{13} \mathrm{C}$ and ${ }^{15} \mathrm{~N}$ resonances of this protein and predicted its secondary structure. The NMR-chemical shift data indicate that Bet $v 1.0102$ is composed of three $\alpha$-helices and a seven stranded $\beta$-sheet, in agreement with the known structure of the hyperallergenic isoform Bet v 1.0101 (Bet v 1a). Our resonance assignments create the foundation for detailed characterization of the dynamic properties of Bet $\mathrm{v} 1$ isoforms by NMR relaxation measurements.
\end{abstract}

Keywords NMR resonance assignment $\cdot$ Bet v $1 \cdot$ Birch . Allergen

Martin Tollinger

martin.tollinger@uibk.ac.at

1 Institute of Organic Chemistry, Center for Molecular Biosciences Innsbruck (CMBI), University of Innsbruck, Innrain 80/82, 6020, Innsbruck, Austria

2 Department of Molecular Biology, University of Salzburg, Hellbrunnerstraße 34, 5020 Salzburg, Austria

\section{Biological context}

Bet $\mathrm{v} 1$ is a highly immunogenic protein that represents the main cause for allergic sensitization against birch pollen (Ipsen and Lowenstein 1983). In the temperate climate zone of the northern hemisphere, an estimated 100 million people are allergic to birch pollen, up to $90 \%$ of individuals that are sensitized to birch pollen exhibit serum IgE reactivity towards Bet v 1 (Moverare et al. 2002). This allergen belongs to the family of pathogenesis-related proteins of class 10 (PR-10), which are found in a multitude of different plants (Fernandes et al. 2013). The exact function of these proteins is still unknown, but a key role in defence of plants is assumed, as they are encoded by genes that are activated in response to different kinds of abiotic and biotic stress.

Naturally occurring Bet $\mathrm{v} 1$ is a composition of different isoforms with a molecular mass around $17.5 \mathrm{kDa}$, which share high sequential identities but can have a drastically different allergenic potential (Ferreira et al. 1996). To date more than twenty isoforms are listed by the IUIS Allergen Nomenclature Sub-Committee (http://www.allergen.org). With $35 \%$ of total Bet $\mathrm{v} 1$ in grained pollen, the hyperallergenic isoform Bet $v 1.0101$ (Bet $v 1 \mathrm{a}$ ) is the most abundant one (Ferreira et al. 1996). Experiments with sera of birch pollen allergic individuals showed that Bet v 1.0101 has the ability to induce a high level of $\operatorname{IgE}$ antibody production, which results in type I allergic reactions (Wagner et al. 2008). This is contrasted by Bet $\mathrm{v}$ 1.0102 (Bet $\mathrm{v} 1 \mathrm{~d}$ ), which possesses a sequence identity of $95.6 \%$ to Bet $\mathrm{v} 1.0101$ but activates IgG4 expression (Wagner et al. 2008). The hyperallergenic isoform Bet $\mathrm{v}$ 1.0101 thus plays an important role for allergic sensitization, while the hypoallergenic Bet $v 1.0102$ initiates the defending immune response. Furthermore, hypoallergenic isoforms are potential candidates for allergen-specific 
immunotherapy (Valenta et al. 2016). Very recent studies hypothecate that these different immunological properties may result from a varying dynamical behavior and fold stabilities (Freier et al. 2015; Machado et al. 2016).

The three-dimensional structures of numerous Bet v 1 isoforms and mutants are available in the literature (Fernandes et al. 2013). Bet $\mathrm{v}$ onefolds into a curved seven-stranded antiparallel $\beta$-sheet, along with two short $\alpha$-helices and an extended C-terminal helix, which create an expanded internal cavity, as it is typical for the PR-10 protein family. Of note, Bet $v 1$ structures that are available in the protein data base (PDB) exhibit only small differences, with backbone pair-wise rmsd values between 1.5 and $2 \AA$. For Bet v 1.0102 a three-dimensional structure has not been reported so far. Homologous PR-10 proteins found in fruits and vegetables with similar three-dimensional structures can elicit allergic cross-reactions with Bet v 1-specific IgE antibodies, including apples, cherries, peaches and others (Mills and Shewry 2004).

Here we present the solution NMR backbone and side chain assignment of hypoallergenic Bet v 1.0102 and a chemical shift-derived three-dimensional structure model of this protein created by CS-Rosetta. Chemical shift assignments of Bet $\mathrm{v} 1$ are the prerequisite for future NMR dynamics studies of this protein.

\section{Methods and experiments}

\section{Protein expression and purification}

For recombinant protein production the vector pET28b containing codon-optimized DNA of Bet v 1.0102 was used. The expression and purification protocol was adapted from Wallner et al. (2009). Protein expression in E. coli strain BL21 (DE3) Star was carried out in $11 \mathrm{M} 9$ minimal medium including $25 \mu \mathrm{g} / \mathrm{ml}$ kanamycin enriched with ${ }^{15} \mathrm{NH}_{4} \mathrm{Cl}$ (Cambridge Isotope Laboratories) and ${ }^{13} \mathrm{C}_{6}$-D-glucose (Sigma-Aldrich) for isotope labeling at $37^{\circ} \mathrm{C}$. After induction with $0.5 \mathrm{mM}$ IPTG at $\mathrm{OD}_{600}=0.6-0.8$, the culture was grown overnight at $16^{\circ} \mathrm{C}$ and harvested by centrifugation at $2050 \times g$. For cell resuspension a buffer containing $25 \mathrm{mM}$ imidazole, $0.1 \%$ (v/v) Triton $\times 100$ and $0.5 \mathrm{M}$ urea was used. The cells were lysed by three cycles of freezing (liquid nitrogen) and thawing (water bath at $\left.37^{\circ} \mathrm{C}\right)$. First, DNAse I $(1 \mu \mathrm{g} / \mathrm{ml})$ and after $20 \mathrm{~min}$ of shaking, solid $\mathrm{NaCl}$ was added to a final concentration of $200 \mathrm{mM}$. The mixture was centrifuged at $9500 \times g$ for $30 \mathrm{~min}$ and the supernatant was collected. Under constant stirring on ice solid $\mathrm{NaCl}$ and $\mathrm{NaH}_{2} \mathrm{PO}_{4}$ were slowly added to a concentration of 1 and $0.5 \mathrm{M}$, respectively. After $2 \mathrm{~h}$ of stirring the precipitated proteins were collected at $9500 \times g$ for $30 \mathrm{~min}$ and the supernatant containing Bet $\mathrm{v} 1.0102$ was filtered through a $45 \mu \mathrm{m}$ filter. Bet v 1.0102 was purified by hydrophobic interaction
Fig. 1 Assigned ${ }^{1} \mathrm{H}-{ }^{15} \mathrm{~N}-\mathrm{HSQC}$ spectrum of Bet v 1.0102 in $10 \mathrm{mM}$ sodium phosphate, $50 \mathrm{mM} \mathrm{NaCl}, 10 \% \mathrm{D}_{2} \mathrm{O}$ at $\mathrm{pH}$ 7.0, $298 \mathrm{~K}, 500 \mathrm{MHz}$. $\mathrm{NH}_{2}$ side chain resonances are connected by horizontal lines. Asterisks indicate the positions of residues below the intensity cut-off

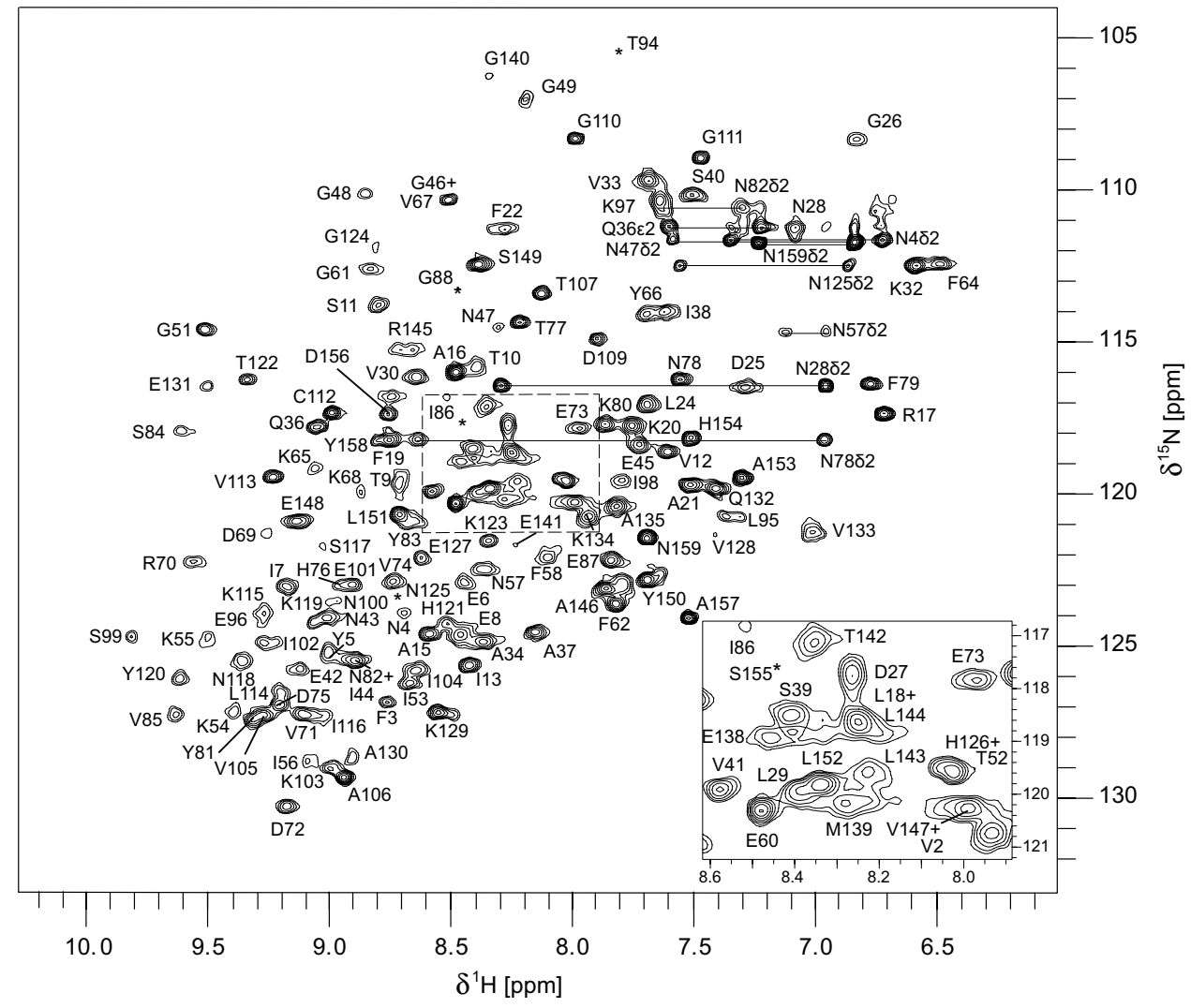


chromatography using $3 \times 5 \mathrm{ml}$ phenylsepharose columns (HiTrap ${ }^{\mathrm{TM}}$ Phenyl FF, GE Healthcare) at a flow rate of $2 \mathrm{ml} /$ min. After the protein solution was loaded, a linear gradient of $30 \mathrm{ml}$ with $0.2 \mathrm{M} \mathrm{NaH}_{2} \mathrm{PO}_{4}$ and $1 \mathrm{M} \mathrm{NaCl}, \mathrm{pH} 4.2$ was performed to remove urea. For protein elution, a linear gradient of $180 \mathrm{ml}$ using $25 \mathrm{mM}$ TrisHCl pH 9.3, 8\% (v/v) 2-propanol was applied. Bet v 1.0102 containing fractions were collected and concentrated by Amicon Ultra Centrifugal Filters with a cut-off of $3000 \mathrm{Da}$ (Millipore). As final purification step size exclusion chromatography was performed using a $120 \mathrm{ml}$ gel filtration column (HiLoad 16/600 Superdex 75 prep grade, GE Healthcare) with $5 \mathrm{mM}$ sodium phosphate buffer, $\mathrm{pH} 8.0$ at a flow rate of $1 \mathrm{ml} / \mathrm{min}$. An ÄKTAprime ${ }^{\mathrm{TM}}$ plus chromatography system (GE Healthcare) was used for all chromatographic steps with an integrated UV-detector for protein detection at $280 \mathrm{~nm}$. The protein concentration was determined using a NanoPhotometer ${ }^{\circledR}$ (Implen). Expression and purification of Bet v 1.0102 were monitored by sodium dodecyl sulfate polyacrylamide gel electrophoresis (SDS-PAGE) using $15 \%$ gels. Purified Bet v 1.0102 was dialyzed against $50 \mathrm{mM} \mathrm{NaCl}$, $10 \mathrm{mM}$ sodium phosphate buffer, $\mathrm{pH} 7.0$ for NMR resonance assignment experiments.

\section{NMR spectroscopy}

The following spectra were recorded for NMR resonance assignment on a $500 \mathrm{MHz}$ Agilent DirectDrive spectrometer at $298 \mathrm{~K}: 2 \mathrm{D}{ }^{1} \mathrm{H}^{-15} \mathrm{~N}-\mathrm{HSQC},{ }^{1} \mathrm{H}^{-13} \mathrm{C}-\mathrm{HSQC}$, and 3D HNCO,
HNCACB, CBCA(CO)NH, (H)CC(CO)NH-TOCSY, H(CC) (CO)NH-TOCSY, and ${ }^{1} \mathrm{H}^{15} \mathrm{~N}-\mathrm{HSQC}-\mathrm{TOCSY}$. The protein concentration for these NMR measurements was $0.8 \mathrm{mM}$ of ${ }^{15} \mathrm{~N} /{ }^{13} \mathrm{C}$ labeled Bet v 1.0102 in $10 \mathrm{mM}$ sodium phosphate, $50 \mathrm{mM} \mathrm{NaCl}, 90 \% \mathrm{H}_{2} \mathrm{O} / 10 \% \mathrm{D}_{2} \mathrm{O}(\mathrm{v} / \mathrm{v})$ at $\mathrm{pH}$ 7.0. Data processing was done using NMRPipe (Delaglio et al. 1995) and for resonance assignment the program CcpNmr Analysis (Vranken et al. 2005) was used.

\section{Assignment and secondary structure}

The ${ }^{1} \mathrm{H}^{15} \mathrm{~N}-\mathrm{HSQC}$ spectrum of Bet $\mathrm{v} 1.0102$ is shown in Fig. 1. Backbone amide ${ }^{1} \mathrm{H}-{ }^{15} \mathrm{~N}$ resonance assignment was obtained for 143 out of 151 non-proline residues, which corresponds to $94.7 \%$. In addition, $96.9 \%$ of $\mathrm{C} \alpha, 96.9 \%$ of $\mathrm{C} \beta$ and $94.0 \%$ of $\mathrm{CO}$ resonances were assigned, and assignment of side chain protons is $87.4 \%$ complete. Furthermore, side-chain ${ }^{13} \mathrm{C}$ resonances beyond $\beta$-positions and side-chain amides in Asn and Glu $\left({ }^{15} \mathrm{~N}\right.$ and $\left.{ }^{1} \mathrm{H}\right)$ were assigned partially. The chemical shift data of Bet $v 1.0102$ have been deposited at the Biological Magnetic Resonance Data Bank (BMRB) with the accession number 27040.

Using the Bet $\mathrm{v} 1.0102$ chemical shifts $(\mathrm{HN}, \mathrm{N}, \mathrm{C} \alpha, \mathrm{C} \beta$ and $\mathrm{CO}$ ), the secondary structure elements of the protein were predicted by TALOS+ (Shen et al. 2009) (Fig. 2a). Our data show that this protein contains seven $\beta$-strands $(\beta 1-\beta 7)$ and two short helices $(\alpha 1-\alpha 2)$, as well as a long $\mathrm{C}$-terminal helix ( $\alpha 3)$. In addition, a three-dimensional model of the

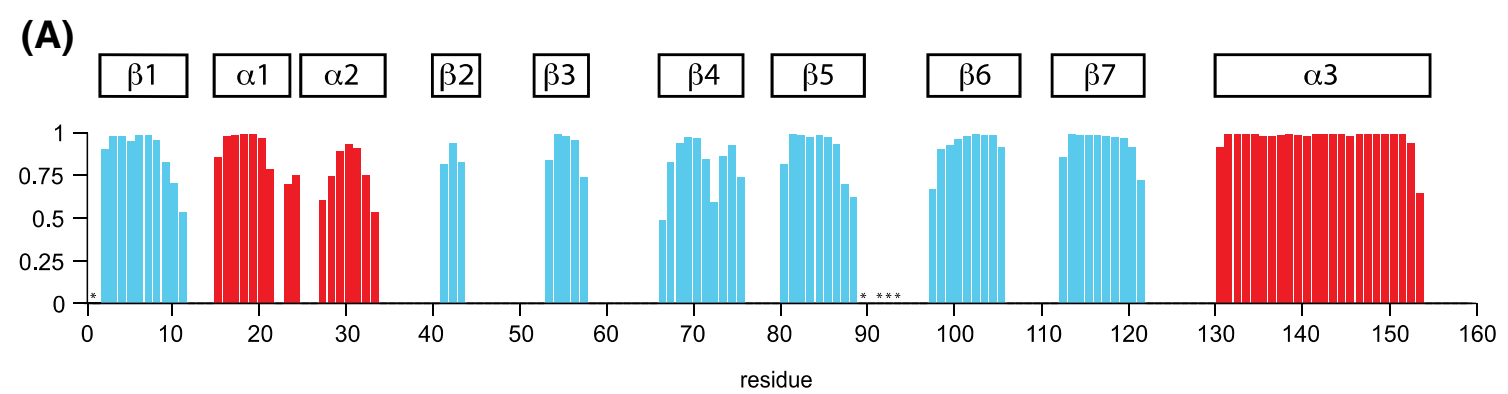

(B)

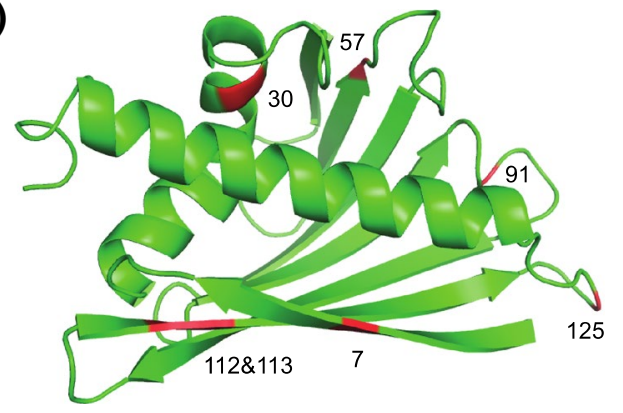

Fig. 2 A TALOS+ prediction of secondary structure elements of Bet v 1.0102 derived from $\mathrm{HN}, \mathrm{N}, \mathrm{C} \alpha, \mathrm{C} \beta$ and $\mathrm{CO}$ chemical shifts. The secondary structure probability is reflected by the height of the bars (blue $\beta$-strands, red $\alpha$-helices). Unassigned backbone amide $\mathrm{NH}$ resonance are indicated by asterisks. For comparison, the secondary structure elements of Bet $\mathrm{v} 1.0101(\alpha 1-\alpha 3$ and $\beta 1-\beta 7)$ are shown above. B Lowest energy CS-ROSETTA structure model of Bet $\mathrm{v}$ 1.0102. Amino acids that are different in Bet $v 1.0102$ compared to Bet $\mathrm{v} 1.0101$ are highlighted in red (T7I, F30V, S57N, I91V, S112C, I113V, D125N) 
protein was generated using CS-ROSETTA (Lange et al. 2012) (Fig. 2b). In this structure, Bet v 1.0102 consists of a long C-terminal helix that is embraced by a curved, seven-stranded antiparallel $\beta$-sheet. Helices $\alpha 1$ and $\alpha 2$ form a V-shaped support for helix $\alpha 3$, creating a large internal cavity, consistent with the canonical PR-10 fold (Fernandes et al. 2013).

Taken together, the Bet v 1.0102 chemical shift data indicate no significant structural difference between the hypoallergenic isoform Bet v 1.0102 and the hyperallergenic isoform Bet v 1.0101 (Gajhede et al. 1996). However, the observed variability in resonance intensities is an indication for the dynamic nature of this protein. A detailed NMR spectroscopic investigation of the dynamic properties of Bet $\mathrm{v} 1$ proteins in the context of their observed immunologic features is currently being performed at our laboratory. In addition, the NMR chemical shift assignments of Bet $\mathrm{v}$ 1.0102 build the basis for epitope mapping and ligand binding studies.

Acknowledgements Open access funding provided by Austrian Science Fund (FWF). This work was supported by the Austrian Science Fund FWF (P26849).

Open Access This article is distributed under the terms of the Creative Commons Attribution 4.0 International License (http://creativecommons.org/licenses/by/4.0/), which permits unrestricted use, distribution, and reproduction in any medium, provided you give appropriate credit to the original author(s) and the source, provide a link to the Creative Commons license, and indicate if changes were made.

\section{References}

Delaglio F, Grzesiek S, Vuister GW, Zhu G, Pfeifer J, Bax A (1995) NMRPipe: a multidimensional spectral processing system based on UNIX pipes. J Biomol NMR 6:277-293

Fernandes H, Michalska K, Sikorski M, Jaskolski M (2013) Structural and functional aspects of PR-10 proteins. FEBS J 280:1169-1199
Ferreira F, Hirtenlehner K, Jilek A et al (1996) Dissection of immunoglobulin $\mathrm{E}$ and $\mathrm{T}$ lymphocyte reactivity of isoforms of the major birch pollen allergen Bet $\mathrm{v}$ 1: potential use of hypoallergenic isoforms for immunotherapy. J Exp Med 183:599-609

Freier R, Dall E, Brandstetter H (2015) Protease recognition sites in Bet $\mathrm{v}$ 1a are cryptic, explaining its slow processing relevant to its allergenicity. Sci Rep 5:12707

Gajhede M, Osmark P, Poulsen FM et al (1996) X-ray and NMR structure of Bet v 1, the origin of birch pollen allergy. Nat Struct Biol 3:1040-1045

Ipsen H, Lowenstein H (1983) Isolation and immunochemical characterization of the major allergen of birch pollen (Betula verrucosa). J Allergy Clin Immunol 72:150-159

Lange OF, Rossi P, Sgourakis NG et al (2012) Determination of solution structures of proteins up to $40 \mathrm{kDa}$ using CS-Rosetta with sparse NMR data from deuterated samples. Proc Natl Acad Sci USA 109:10873-10878

Machado Y, Freier R, Scheiblhofer S et al (2016) Fold stability during endolysosomal acidification is a key factor for allergenicity and immunogenicity of the major birch pollen allergen. J Allergy Clin Immunol 137:1525-1534

Mills ENC, Shewry PR (2004) Plant food allergens. Blackwell Science, Oxford

Moverare R, Westritschnig K, Svensson M et al (2002) Different IgE reactivity profiles in birch pollen-sensitive patients from six European populations revealed by recombinant allergens: an imprint of local sensitization. Int Arch Allergy Immunol 128:325-335

Shen Y, Delaglio F, Cornilescu G, Bax A (2009) TALOS plus : a hybrid method for predicting protein backbone torsion angles from NMR chemical shifts. J Biomol NMR 44:213-223

Valenta R, Campana R, Focke-Tejkl M et al (2016) Vaccine development for allergen-specific immunotherapy based on recombinant allergens and synthetic allergen peptides: lessons from the past and novel mechanisms of action for the future. J Allergy Clin Immunol 137:351-357

Vranken WF, Boucher W, Stevens TJ et al (2005) The CCPN data model for NMR spectroscopy: development of a software pipeline. Proteins 59:687-696

Wagner S, Radauer C, Bublin M et al (2008) Naturally occurring hypoallergenic Bet $\mathrm{v} 1$ isoforms fail to induce $\mathrm{IgE}$ responses in individuals with birch pollen allergy. J Allergy Clin Immunol 121:246-252

Wallner M, Himly M, Neubauer A et al (2009) The influence of recombinant production on the immunologic behavior of birch pollen isoallergens. PLoS ONE 4:e8457 